\title{
Apropiacionismos y resignificaciones de la obra "Various small fires” de Ed Ruscha. Appropriationism and reinterpretations of the artwork "Various small fires” of Ed Ruscha.
}

\author{
Hortensia Mínguez García \\ Dra. Bellas Artes \\ Universidad Autónoma de Ciudad Juárez, \\ Chihuahua, México. \\ hminguez@uacj.mx \\ horteminguez@gmail.com
}

Recibido 01/10/2016

Aceptado 03/12/2016
Revisado 30/11/2016

Publicado 01/06/2017

\section{Resumen}

Durante más de cincuenta años, los libros de artista de Ed Ruscha han favorecido una particular tendencia apropiacionista. Por ejemplo, su obra "Various Small Fires" (1964) ha sido "reescrita" por autores como Bruce Nauman (1969), Jonathan Monk (1969), Lucas Batten y Jonathan Sadler (2003), Thomas Galler (2009), Scott McCarney (2010), Doro Boehme y Eric Baskauskas (2010) y Marcella Hackbard (2010), generándose con ello, un movimiento de apropiacionionismos y resignificaciones que se cierra, al menos temporalmente, con "Various Small Shipwreck... and big Fires” (2016) de autoría propia.

El objetivo del presente texto, es el de analizar dichas obras y sus relación con "Various Small Fires", tomando a Ed Ruscha
For over fifty years, the artist's books of Ed Ruscha have generated an appropriationist trend around the world. For example, his work "Various Small Fires" (1964) has been "rewritten" by authors such as: Bruce Nauman (1969), Jonathan Monk (1969), Luke Batten and Jonathan Sadler (2003), Thomas Galler (2009), Scott McCartney (2010), Doro Boehme and Eric Baskauskas (2010) and Marcella Hackbard (2010), etc. All of them have generated an appropriationist movement and resignifications which is closed, at least temporarily, with "Various Small Shipwreck ... and big Fires” (2016) of own authorship.

The objetive of this text is to analyze these works and their relation to "Various Small Fires", taking Ed Ruscha as founder of discourses, and the book itself, as an icon for

Para citar este artículo

Mínguez García, H. (2017). Apropiacionismos y resignificaciones de la obra "Various small fires" de Ed Ruscha.Tercio Creciente,-13, págs. 31-48. https://dx.doi.org/10.17561/rtc.mextra1.2 
como fundador de discursividad, y al libro en sí, como icono para la memoria colectiva de los amantes de este género artístico y para la historia del hombre en general. Un análisis que nos ayudará a visualizar cómo algunos artistas bajo la figura del replicante han rehecho el estilo ruschiano para la construcción de nuevos discursos que, inevitablemente refractan, nuestras actuales prácticas de creación y producción editorial en un mundo cada vez más globalizado y dominado por los medios de comunicación masiva. the collective memory of lovers of this artistic genre and our history, too. Aso, this analysis will help us visualize how some artists under the figure of replicant have remade the style of Ruscha for the construction of new discourses that, inevitably, refracted our current practices of creating and publishing in an increasingly globalized world dominated by mass media.

Palabras clave / Keywords

Libro de artista, libro-arte, ediciones artísticas, Ed Ruscha, apropiacionismo, Varios pequeños fuegos.

Artist book, Art-book, artistic editions, Ed Ruscha, Appropriationism, Various small fires.

Para citar este artículo

Mínguez García, H. (2017). Apropiacionismos y resignificaciones de la obra "Various small fires" de Ed Ruscha.Tercio Creciente, 13, págs. 31-48. https://dx.doi.org/10.17561/rtc.mextra1.2 
Revista de Estudios en Sociedad, Artes y Gestión Cultural www.terciocreciente.com http://revistaselectronicas.ujaen.es/index.php/RTC
Enero 2017

Investigación

\section{1.- Preámbulo}

El género del libro de artista o Libro-arte, ha atraído como cualquier otro medio de expresión artística, autores que manejan la práctica apropiacionista como método creativo. Es decir, artistas que actúan como replicantes ${ }^{1}$, pues hacen réplicas de obras ajenas pero no como copias, sino como homenaje, a la vez que resignificación; pues no olvidemos que uno de los principios metodológicos y motivacionales del apropiacionista como productor, es que el mismo lecto-espectador construya y urda el significado de la obra que se le presenta ante él, y además, se interrogue acerca de cuál es su postura ante dicha adaptación.

Quien más ha cautivado replicantes dentro del género del libro de artista es Edward Ruscha (1937-) Artista estadounidense asociado principalmente al movimiento del Arte Pop pero con un profundo anclaje a la "vertiente fotográfica y documental” (Del Río, 2002, p. 1) usual al Arte como archivo y el Arte conceptual de los sesenta. Los aportes de Ruscha han sido múltiples, yendo desde la pintura, la fotografía, la gráfica y el libro de artista. Sin embargo, una de las contribuciones indirectas más interesantes de su trabajo -y curiosamente, la menos estudiada-, ha sido la estela que Ruscha ha venido dejando en otros autores apropiacionistas. Un aporte que, le hace merecedor de la insignia de fundador de discursividades desde la perspectiva foucaultiana (1990), dada la cantidad de impulsos alegóricos que ha suscitado hasta la fecha ${ }^{2}$.
A lo largo de su carrera profesional, Ruscha ha producido 18 libros de artista. Entre los más famosos: "Twentysix gasoline stations" (1962), "Various small fires" (1964) -en el cual nos centraremos más adelante como caso de estudio e hito de producción replicante-, "Some Los Angeles apartments" (1965), "Every building on the Sunset Strip" (1966), "Thirtyfour parking lots" (1967), "Nine swimming pools and a broken glass” (1968) o “A few palm trees” (1971), entre otros.

Todos estos libros mantienen más o menos el mismo estilo ruschiano. Fotolibros diseñados a partir de imágenes de varias autorías ${ }^{3}$ con un particular sentido de la retícula como baliza que demarca nuestro recorrido, además de un excelente manejo de la tipografía en sentido retórico.

Por su parte, el estilo editorial de Ruscha fue muy transgresor para su época. Formalmente, fueron ediciones ideadas bajo principios bastante democráticos: libros de pequeño formato y corta extensión -entre 32 a 62 páginas aproximadamente-, impresos en offset y en su mayoría, en blanco y negro. Todos ellos, ejemplares sin firmar, ni numerar, de tiraje abierto, variable y relativamente grande (entre 400 a 4000); ejemplares en su mayoría reeditados con cierta periodicidad, con materiales baratos, encuadernación americana y asequibles por sus precios económicos, al menos, en un inicio ${ }^{4}$

Discursivamente, los libros de artista de Ruscha son piezas que de forma explícita, 
muestran aquello que enuncian: "Twentysix Gasoline Stations” (1962) documenta gasolineras, "Various Small Fires" (1964) registra pequeños fuegos, "Every Building on the Sunset Strip" (1966) una calle, etc 5 . De hecho, en la gran mayoría de sus libros, Ruscha goza articular imágenes del paisaje, el ambiente, la arquitectura y el urbanismo de Los Ángeles, fotografiando para ello, todo aquello que compone y caracteriza a la ciudad como sello identitario: sus palmeras, automóviles, edificios, gasolineras, etc. Ad hoc, Ruscha se deleita con la producción de libros monotemáticos que recogen series fotográficas de un mismo motivo pero con pequeñas variables: diferentes tipos de palmeras, varios fuegos, algunas piscinas, por ejemplo. En suma, libros enigmáticos y sobrios por su característica linealidad secuencial y por cómo el autor maneja la iteración como estrategia narrativa.

Otra de las características más importantes del estilo ruschiano es el tipo de imágenes que componen sus libros. En este caso, fotografías de lugares u objetos "banales" abordados como readymades, que al aglutinarse afianzan una línea estética relativa al objeto cosificado, manejado de manera inexpresiva e indiferente en pro de lo conceptual ${ }^{6}$. En nuestra opinión, un anodismo intencional rebasado por el potencial polisemántico que Ruscha consigue a través del formato del libro y sus posibilidades narrativas.

Prácticamente, esta ambigüedad polisémica impulsada por el aparente anodismo ruschiano, entre otras puntos que iremos viendo al paso, es la que ha favorecido que muchos de sus libros de artista hayan sido apropiados y resignificados una y otra vez por autores de todas las partes del mundo. Cientos de trabajos que, gracias a la labor de Jeff Brouws, Wendy Burton y Hermann Zschiegner, podemos visualizar a vuela pluma en la obra "Various
Small Books by Ed Ruscha”. Un libro editado por The MIT Press a principios de 2013 que recopila un total de noventa y un piezas de autores de talla internacional y que, desde nuestro punto de vista integra un extraordinario movimiento apropiacionista. Si cabe, un movimiento que, más allá de profundizar hermenéuticamente en la obra ruschiana, ha vehiculizado la superposición de nuevos sentidos hacia su obra, utilizándola como trampolín para su recontextualización y resignificación. Como diría Batjin (1990), un movimiento reflejo de un "sistema colectivo compartido de herencias" (p. 366) que pone en evidencia, la huella del pasado pero, también el estatus de nuestras formas, modos y valores hacia la producción, la circulación y el consumo del arte en la actualidad tanto a nivel estético, como ético o sociopolítico; más que nunca, amigables con los discursos posmodernos y los gustos inmanentes a la era neobarroca. ${ }^{7}$ (Calabrese, 1987)

Por todo ello, obras como "Twentysix Gasoline Stations" (1962) o "Various Small Fires" (1964) entre otras, son hoy para nosotros, íconos seculares de nuestro tiempo. Primero, en cuanto al giro discursivo del autor hacia el manejo de los medios en sí. Es decir, por la simpleza con la que Ruscha rompió con las formalidades del género fotográfico y el arte en general, pues sus obras no son arte fotográfico, sino arte con forma de libro: lugar común para ser visto y ser revisitado de manera intimista y ensimismada tantas veces como se desee, sin mediación alguna: ni galeristas, ni vitrinas, ni tan siquiera guantes ${ }^{8}$. Y segundo, por cómo operó discursivamente los temas, la técnica, los formatos de producción y mercantilización de la obra; siempre, desde el paradigma de la dislocación de lo común en la cultura de su tiempo. 
Revista de Estudios en Sociedad, Artes y Gestión Cultural www.terciocreciente.com

http://revistaselectronicas.ujaen.es/index.php/RTC
Enero 2017

Investigación

\section{2.- "Various small fires and milk" y sus replicantes.}

En este espacio, nos centraremos en el análisis de uno de los trabajos de Ruscha "Various small fires and milk" y sus replicantes por tratarse de una de las obras más enigmáticas y reapropiadas del autor. Esta obra es un libro de pequeño formato, (17.8 x $14.0 \mathrm{~cm}$.), editado en 1964 con un tiraje de 400 ejemplares y reeditado en 1970 con 3000 más. Concretamente, el segundo de sus 18 libros de artista. En él, Ruscha reprodujo imágenes de pequeñas llamas a través de fotografías de cerillas, estufas, un zipper funcionando, varias personas fumando un cigarrillo, un puro y en pipa, una vela prendida, un soplete, etc. Quince imágenes fotográficas en total, impresas con un tono amarillento sobre papel de color blanco (obviamente, en alusión a la calidez del fuego), y dispuestas a la derecha de cada doble página. Les sigue, impresa en blanco y negro, la fotografía de un vaso lleno de leche y frente a él, la esquina de un plato vacío en primer plano. Al final, 10 hojas en blanco. En cuanto al título de la portada, se lee "Various Small Fires" con tipografía “Clarendon Blk BT” en mayúsculas, en negro sobre fondo blanco. Adentro, Ruscha matiza la obra con un subtítulo: "Various small fires and milk.”

Como la gran mayoría de sus trabajos, la secuencia narrativa de esta obra en concreto se obtiene a través del manejo de un único eje temático: tipos de fuegos. En este caso, fuegos banales, sin transcendencia alguna.

Esta dinámica monoserial viene a romperse cuando el lector se topa con un vaso de leche a modo de epílogo; lector que de repente se ve invadido por varias incertidumbres. Acaso, ¿el fuego como tema tiene algún trasfondo?
¿Por qué son fuegos triviales? ¿Tiene este libro alguna conexión con el primero de sus libros, el de las gasolineras? ¿Por qué cierra Ruscha la pieza con un vaso de leche y no de agua? En fin, no pareciera haber una respuesta única, sino más bien, el vestigio de un deseo por parte de Ruscha; el de mecerse con donaire e ironía entre el surrealismo, -por su paranoico deseo de transfigurar el sentido de la lógica-, y un trasfondo claramente intimista ${ }^{9}$.

Varios son los artistas que se han apropiado de la obra de "Various Small Fires" para fines propios. Veámoslos.

\section{“Various Small Fires” de Bruce Nauman (1968)}

El primer artista que tomó la obra "Various Small Fires and Milk" fue Bruce Nauman, quien en 1968 adquirió un ejemplar de Ruscha, rompió las hojas y una a una las fue quemando. A la postre, decenas de fotografías en blanco y negro documentan el proceso de la quema de hojas sobre el piso de madera del estudio de Nauman, atestiguando de este modo, un consumo que trasgrede irónicamente el concepto del arte de la lectura por medio de la consumación literal de la obra en términos físicos.

La pieza, por su parte, busca generar una tensión constante a través del registro iterado de la quema. Para ello, Nauman maneja el mismo encuadre para todas las tomas. Al centro, muestra una de las hojas ardiendo mientras que, a la izquierda del plano, se entrevé la esquina de la hoja que le precederá; la siguiente víctima "awaiting its conflagration ${ }^{10}$ " (Zschiegner, Brouws y Burton, 2013, p. 34) 
Una vez realizadas las tomas fotográficas, Nauman montó reticularmente 15 de ellas en un libro de artista en forma de pliego. Para ello utilizó una hoja de 125 x $118 \mathrm{~cm}$., aproximadamente. Primero, plegada por la mitad en sentido horizontal y luego, en cuatro hasta formar un cuadernillo cerrado de $24,5 \mathrm{x}$ $32 \mathrm{~cm}$.

Este formato en concreto lo utilizó a su vez, para jugar con el título de la obra. Así, en lugar de leerse Burning all the fires, en la portada se lee, "Urning all the ires" ya que la B y la F quedan relegadas al espacio de la contraportada. Un juego de palabras que como ya anotó Zschiegner (2013) enmascara hasta cierto punto un acto subversivo, puesto que "urning all the ires" podría traducirse como: la quema ("ires" traducible como urna) del "trébol", "homófono del verbo ganar". Una clara declaración de intenciones por parte de Nauman. Si cabe, una provocación: la descarada licencia "de abordar directamente la obra de otro artista, dándose cuenta de que ese diálogo es potencialmente no recíproco y no consensual.” (p. 35)

Asimismo, es importante recalcar que secuencialmente Nauman omitió por completo las hojas en blanco y la del vaso de leche de "Various small fires and milk". Una decisión que refuerza dicho concepto a la par que, pone en evidencia, que Nauman estaba más interesado en el efecto catalítico que la quema repetitiva de las hojas de Ruscha pudiera generar en el lecto-espectador.

"Small fires burning [after Ed Ruscha after Bruce Nauman after]" (2003) y “\& Milk" (2004) por Jonathan Monk.

En 2003, otro de los ejemplares de "Various small fires and milk" fue incinerado. En esta ocasión a manos de Jonathan Monk (1969) quien filmó la quema en formato de $16 \mathrm{~mm}$ para la obtención de un loop de 6 minutos de duración. Un acto performático titulado "Small fires burning [after Ed Ruscha after Bruce Nauman after]” por medio del cual Monk, no sólo dio paso a una especie de movimiento heteroglósico de intertextualidades, sino con el que además, denunciaba el funcionamiento del mercado del arte. No olvidemos que, a cada acción apropiacionista de la obra de Ruscha, el precio de las ediciones aumentaba exponencialmente de valor en el mercado, pasando de un valor inicial de apenas unos cincuenta dólares a cientos o miles de ellos. Una tendencia que, año tras año, sigue en alza, contrariando la intención originaria de Ruscha de generar libros a bajo costo; libros asequibles. De ahí que, quizás pudiéramos considerar que "Small fires burning [after Ed Ruscha after Bruce Nauman after]", nos habla del inane sueño ruschiano de escapar al dominio del mercado del arte.

Un año más tarde, con el afán de complementar la exposición del film, Monk volvería a tomar como discurso iniciador la obra de Ruscha y editaría un libro de artista. Hablamos de su pieza " $\&$ Milk (Today is just a copy of yesterday)", un libro de tapa blanda compuesto por 64 páginas que destaca por el tratamiento con el que el artista aborda la reproducción de la imagen del vaso de leche de Ruscha. En particular, cincuenta imágenes que obtuvo reproduciendo la copia de la copia de la imagen del vaso de leche, generando así un discurso fundamentado en el desgaste, la erosión de los detalles y la degeneración de la imagen inicial. Por ende, una doble prédica considerando que somos una cultura que vive de la copia y la reproductibilidad técnica masiva: Primero, porque se evidencia lo absurdo de seguir creyendo platónicamente en lo aurático, lo único u original. Por otra, porque se constata que en la revalorización de la copia, lo azaroso e imperfecto, se trasgrede el concepto de la duplicación como proceso considerado peyorativamente, degenerado. Una trasgresión que, además, incide en la valía del paso del tiempo como factor determinante para la degeneración de una imagen en vistas a la creación de algo nuevo. Digamos, en otras palabras, la valía del tiempo y de la poética de la destrucción como tránsito de lo figurativo a lo abstracto, de lo viejo a lo nuevo. 
Revista de Estudios en Sociedad, Artes y Gestión Cultural
Enero 2017

Investigación

\section{"Various Fires" (2003) por Lucas Batten y Jonathan Sadler.}

La siguiente parada en este proceso alusivo a la obra de "Various Small Fires" de Ruscha fue a manos de los americanos Lucas Batten y Jonathan Sadler, quienes en 2003 diseñaron "Various Fires"11, uno de sus múltiples proyectos desarrollados en colaboración, bajo el nombre de "New Catalogue".

A diferencia de Nauman y Monk, Batten y Sadler acotan su discurso apropiacionista hacia la sátira. Para ello, satirizan a la fotografía con sus tradiciones temáticas y técnicas como género artístico, ahora aterrizados en el tratamiento simple y popularizado del mito ruschiano pero trasgredidos por medio del manejo oportunista de la imagen, tal y como si se tratara de un proyecto de fotografía comercial. De este modo, se observan fotografías a todo color de varios tipos de fuegos: algunos captados fortuitamente durante un viaje que hicieron los autores como una pequeña quema de arbustos secos, un tronco quemándose en una chimenea o la incineración voluntaria de una vieja casa invadida por termitas; otros, escenificados por varias personas quemando periódicos, fumando un cigarrillo, etc.

"Various Fires and Four Running boys" (2009) por Thomas Galler.

Llegado el 2009-2010, relativizar el adjetivo especificativo "pequeño" de la obra ruschiana, se convierte en tema de interés para dos autores: Thomas Galler en 2009 y Scott McCarney, un año más tarde.

A diferencia de la selección de Ruscha con sus fuegos intrascendentes, -una cerilla, un fogón prendido, etc.-, Thomas Galler decide publicar "Various Fires and Four Running boys", artista suizo que ha utilizado la imagen de incendios de manera constante en su carrera. Esta obra se trata de un libro de artista diseñado bajo los mismos parámetros morfológicos y estéticos de Ruscha. Galler se apropia del formato, del estilo tipográfico, reticular y fotográfico. Rehúsa, sin embargo, detalles importantes que le separan de la aparente copia. Por ejemplo, para dejar patente su intención de distanciarse de lo banal, dispone una banda negra en la portada justo donde se ubicaría la palabra "small". Ad hoc con ello, las imágenes que hallamos en su interior no tienen nada de irrelevantes. Hablamos de fotografías que el autor sustrajo directamente de periódicos desde la temprana fecha de 1999, que vienen a captar importantes momentos de conflagración acontecidos en diferentes ciudades del mundo: desde California, Zurich o Belgrado, entre otras. Imágenes que nos permiten visualizar las infinitas e inconexas caras del fuego: desde quemas de espacios públicos por actos de resistencia de pueblos que insurrecta y violentamente se resisten al poder que les oprime, a captaciones de explosiones o incendios como resultado de disturbios, situaciones bélicas, terrorismo, etc. Obviamente, un discurso mucho más explícito que el de Ruscha, pues mientras que éste recurre a la estetización de lo banal por medio de fotografías displicentes, Galler infiere en la visualización de una actualidad asediada por la espectacularización de las trifulcas, de las lidias, del horror.

Al final, Galler ubica la fotografía de cuatro niños que se alejan de la cámara corriendo entre la lluvia de ceniza que cae como confeti. Sus rostros quedan ocultos a la cámara. Se distancian con júbilo, pareciera incluso que se divierten en medio del "espectáculo". Una maravillosa fotografía "a la vez de horrible y sorprendente belleza”, con la que Galler decide cerrar su libro en pro de "cuestionar la imaginería sensacionalista dentro de las representaciones de los medios que son cómplices de la cultura del espectáculo ${ }^{12}$ " (Zschiegner, 2013, p. 199) 


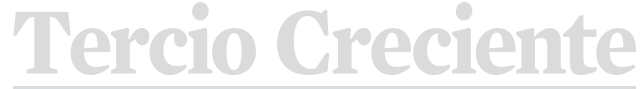

ISSN: 2340-9096

DOI: $10.17561 /$ rtc.mextra1.2
Revista de Estudios en Sociedad, Artes y Gestión Cultural

www.terciocreciente.com

http://revistaselectronicas.ujaen.es/index.php/RTC
Enero 2017

Investigación

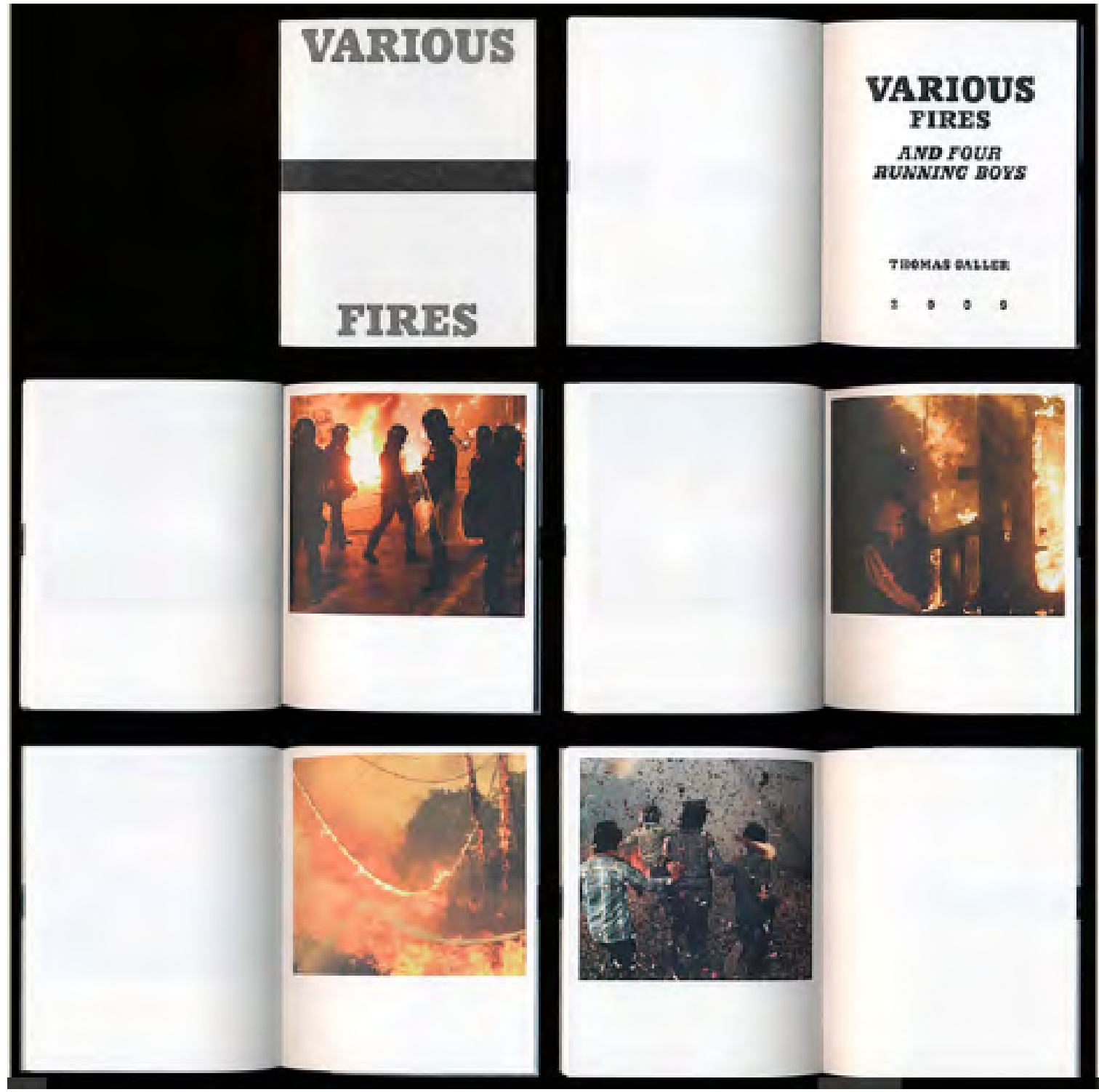

Fig. 1. Fig. 1. Thomas Galler, "Various Fires and Four Running boys", (2009) Libro de artista publicado por Georg Rutishauser, Zurich. Offset, 48p., 21 son fotografías a color 17,8 x 14 cm. Edición: 500 ejemplares, sin firmar ni numerar. Imágenes: Cortesía del autor: Thomas Galler. 
Revista de Estudios en Sociedad, Artes y Gestión Cultural

ISSN: 2340-9096

DOI: $10.17561 /$ rtc.mextra1.2 www.terciocreciente.com http://revistaselectronicas.ujaen.es/index.php/RTC

\section{Investigación}

\section{"Various Fires and MLK” (2010) por Scott McCarney.}

"Various Small Fires and Milk" también inspiró a Scott McCarney en 2010, año en el que produjo su obra "Various Fires and MLK”. En ella, McCarney rescata la poética de Ruscha utilizándola como trampolín para criticar la penosa aplicación de la "Ley de Derechos Civiles" en el contexto de sus orígenes; ley estadounidense que prohíbe diferentes formas de discriminación como la racial, aprobada el mismo año que Ruscha produjo su obra. En la portada, McCarney sustituye la palabra MILK por las siglas MLK en alusión a la figura de Martin Luther King, a quien además encontramos retratado al final del libro. Un mensaje que refuerza en contraste con las imágenes que ubica en su interior. Básicamente, fotografías de incendios (pero no pequeños e insignificantes como los de Ruscha) sino originados por la desobediencia civil en la ciudad de Los Ángeles, (California). Gente, que salía a la calle para proclamar injusticias o atentados contra aquella ley que, por aquel entonces, no amparaba a algunos Estados. Tal es el caso de los disturbios del barrio Watts, donde principalmente residía gente afroamericana en 1965 y que concluyó con 34 personas muertas, más de 1,000 heridas y 600 edificios dañados o destruidos. Del mismo modo, también hallamos imágenes referentes al caso del taxista Rodney King, quien en 1991 fue apaleado brutalmente por la policía por darse a la fuga en plena libertad condicional. Un caso que, tras divulgarse la grabación de un videocámara en la que se veía la brutal paliza, desató la insubordinación de muchos activistas pro minorías así como de civiles generando grandes disturbios ${ }^{13}$.

\section{VARIOUS \\ FIRES \\ AND MLK}

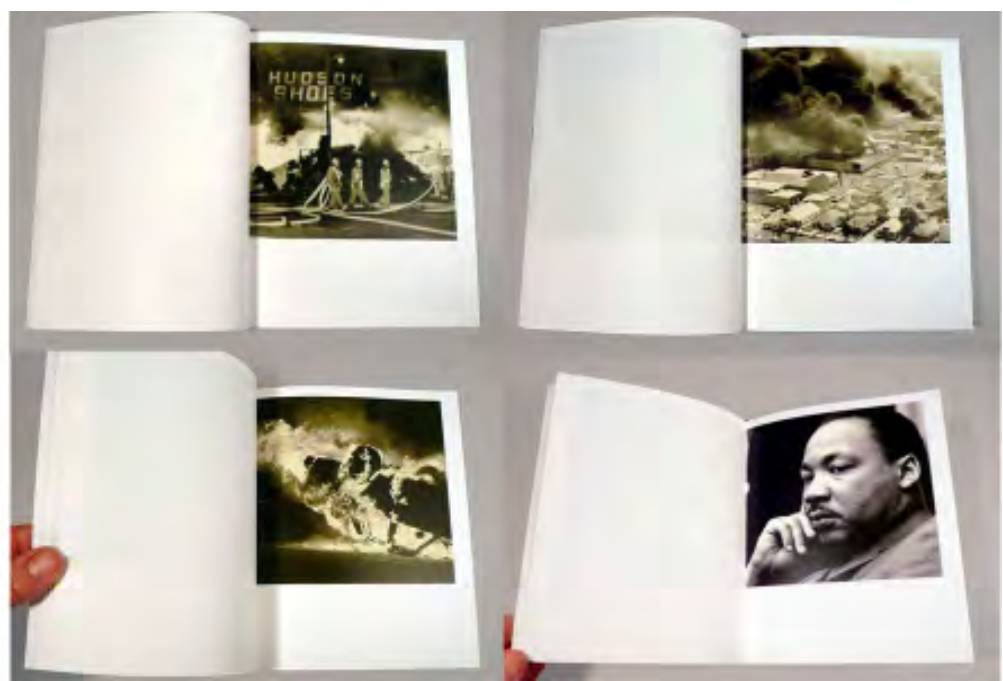

Fig. 2. McCarney, "Various Fires and MLK", (2010) Libro de artista. Formato: 14 x 18 cm., 48 pp. Impresión digital, impreso en Rochester, NY. Imágenes: Cortesía del autor: McCarney. 


\author{
“Various Blanck Pages” (2009) por Doro \\ Boehmen y Eric Baskausas.
}

Dos de los artistas que también forman parte de este movimiento apropiacionista, son Doro Boehmen y Eric Baskausas, quienes en su libro de artista "Various Blanck Pages" (2009), además de aludir a "Various small fires" (1964), nos remiten a otros trabajos como "Nine Swimming pools" (1968), "A Few Palm Trees” (1971) y “Colored People” (1972). Como ya anotamos, la gran mayoría de las obras de Ruscha tienen como particularidad el manejo de hojas en blanco; siempre dispuestas al lado izquierdo, otras veces, ubicadas en diferentes puntos del libro. Por ejemplo, en "Various small fires”, hallamos diez hojas en blanco al final de la pieza; mientras que en "Nine Swimming Pools”, de las 64 páginas que forman el libro, sólo hay un total de 9 fotografías de piscinas, más la imagen de un vidrio roto al final. El resto, son hojas en blanco dispuestas en diferentes intervalos.

Estos espacios son los que Doro y Eric literalmente reprodujeron para la construcción de su libro de artista. Un libro prácticamente blanco construido a partir de las páginas escaneadas de dichos libros, particularmente, de los ejemplares que se encuentran en la colección de Joan Flasch Artists' Book Collection de la SAIC, la School of the Art Institute de Chicago. Una forma de homenajear tanto al autor como a la colección SAIC.

Al caso, lo interesante de la pieza de Doro y Eric es la lectura aumentada que los autores generan a través de dos recursos posmodernos básicos: la intertextualidad y la autorreferencialidad. Primero, en cuanto a la presencia de un texto en otro y por ende, la interconexión que los lectores pudieran hacer entre ambas obras; y por otra, la autorreferencialidad: libros que se referencian a sí mismos como medios que necesariamente requieren ser transitados espacio-temporalmente para ser leídos. Un libro que se narra a sí mismo.

\section{"Various unbaked Cookies and Milk" (2010) por Marcella Hackbard.}

La siguiente de las piezas que comentaremos es la de "Various unbaked Cookies and Milk" publicada en 2010, obra de la americana Marcella Hackbard, artista y docente en Ohio.

Este trabajo se distancia del resto ya que rehúye del manejo directo de la imagen del fuego. Hackbardt prefiere por el contrario, usar fotografías de pequeñas bolas de masa de galletas todavía por cocer, un distanciamiento temporal respecto a toda idea preconcebida, confiada y previsora que cualquier interpretante conocedor de la obra de Ruscha pudiera tener. En suma, un estilo narrativo que por medio de lo ausente, lo no hecho, lo pendiente, deja en suspense al lector acerca de las pretensiones de la autora. Al respecto, Zschiegner, Brouws y Burton (2013) afirman un posible paralelismo entre las galletas no cocidas que nos muestra Marcella y la obra performática de Martha Rosler "Semiotics of the Kitchen” (1975).

Como sabemos, el performance de Martha Rosler constituye una irónica crítica hacia la aún anticuada idea que se posee acerca del papel de la mujer en el espacio cotidiano de la casa en particular, y de la familia y de la sociedad en general. A lo largo de seis minutos de grabación se observa en plano fijo a Rosler, quien nos va instruyendo uno a uno, acerca de los nombres y los usos de diferentes utensilios de cocina (plato, cuchara, puchero, sartén, etc.). Una demostración que Rosler torna paródica al darle formato de show televisivo ya que, el manejo que hace de las herramientas de cocina es a base de golpes y movimientos contenidos pero, violentos y rudos. De este modo, en línea con el Arte archivo tan característico de su época, Rosler alfabetiza y expone los diferentes utensilios de cocina con el afán de enunciar que todos los sistemas, incluido, el lingüístico, replican toda serie de tradiciones fundamentadas en la instrumentalización y la 
Revista de Estudios en Sociedad, Artes y Gestión Cultural

www.terciocreciente.com

http://revistaselectronicas.ujaen.es/index.php/RTC
ISSN: 2340-9096
Investigación opresión de la mujer. Finalmente, Hackbardt nos habla de la perdurabilidad de este papel social atribuido a la figura femenina treinta años más tarde. Bajo líneas pareciera leerse, que el tema aún está crudo; la toma del vaso de leche de Ruscha, tendrá pues que ser postergada de nuevo.

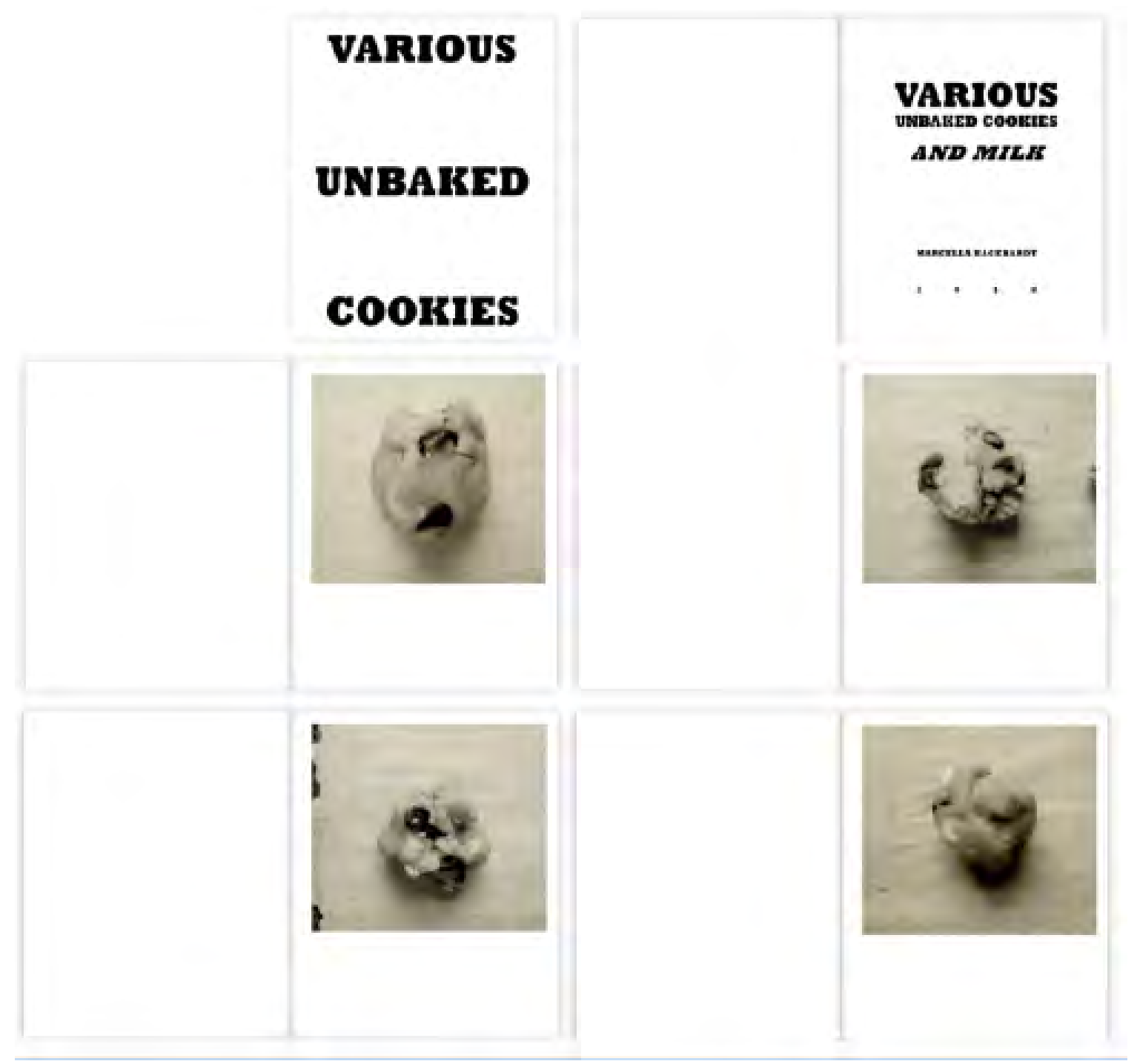

Fig. 3. Marcella Hackbardt, "Various unbaked Cookies and Milk” (2010) Libro de artista. Formato: 20×25 cm. 38 pp. Mount Vernon, Ohio: Cake Press. Imágenes: Cortesía de la autora: Marcella Hackbardt. 
"Various Small Shipwreck... and big Fires", (2016) por Hortensia Mínguez.

"Various small shipwreck... and big fires" (2016) de autoría propia, traducible a "Varios pequeños naufragios... para grandes fuegos", es una de las múltiples obras que podrían aglutinarse al movimiento apropiacionista ruschiano.

El tema desde el cual resignificamos la obra de "Various Small Fires" es un tema delicado y sensible a las problemáticas migratorias del siglo XXI, concretamente, respecto a la crisis migratoria en Europa, también conocida como la crisis de los refugiados en la zona del Mediterráneo.

Desde tiempos remotos, son conocidas las embarcaciones de seres humanos que buscan migrar a geografías más agraciadas climatológica, socioeconómica y políticamente hablando. Saharianos, etíopes, somalís, iraquís, sirios, etc., migrantes del continente africano y de Oriente Medio que huyendo del hambre, la pobreza extrema, la impunidad, la injusticia, e incluso de conflictos armados, guerras y genocidios, a veces, desesperados, buscan una vida digna y prometedora en Europa.

Durante décadas, la crisis migratoria en el Mediterráneo ha sido una constante. Muchas personas, de hecho, viendo la imposibilidad de llegar vía terrestre, prueban suerte desde la ruta del cuerno de África cruzando desde mediterráneo occidental de Marruecos hacia las Islas Canarias o hacia la Península, desde el Mediterráneo central camino a Grecia e Italia, o del Mediterráneo oriental a Turquía o desde Turquía hacia Grecia o Bulgaria. Rutas principales a las que se suman, otras tantas como quienes acceden por Polonia y Austria hacia Alemania.

La interminable guerra civil que azota Siria debatiéndose entre el régimen de Bachar al Asad y la resistencia armada formada por civiles y exsoldados, ha sido uno de los motivos que mayormente ha acrecentado el
El género del libro de artista o Libro-arte, ha atraído como cualquier otro medio de expresión artística, autores que manejan la práctica apropiacionista como método creativo. Es decir, artistas que actúan como replicantes ${ }^{1}$, pues hacen réplicas de obras ajenas pero no como copias, sino como homenaje, a la vez que resignificación; pues no olvidemos que uno de los principios metodológicos y motivacionales del apropiacionista como productor, es que el mismo lecto-espectador construya y urda el significado de la obra que se le presenta ante él, y además, se interrogue acerca de cuál es su postura ante dicha adaptación.

Quien más ha cautivado replicantes dentro del género del libro de artista es Edward Ruscha (1937-) Artista estadounidense asociado principalmente al movimiento del Arte Pop pero con un profundo anclaje a la "vertiente fotográfica y documental" (Del Río, 2002, p. 1) usual al Arte como archivo y el Arte conceptual de los sesenta. Los aportes de Ruscha han sido múltiples, yendo desde la pintura, la fotografía, la gráfica y el libro de artista. Sin embargo, una de las contribuciones indirectas más interesantes de su trabajo -y curiosamente, la menos estudiada-, ha sido la estela que Ruscha ha venido dejando en otros autores apropiacionistas. Un aporte que, le hace merecedor de la insignia de fundador de discursividades desde la perspectiva foucaultiana (1990), dada la cantidad de impulsos alegóricos que ha suscitado hasta la fecha ${ }^{2}$.

A lo largo de su carrera profesional, Ruscha ha producido 18 libros de artista. Entre los más famosos: "Twentysix gasoline stations" (1962), "Various small fires" (1964) -en el cual nos centraremos más adelante como caso de estudio e hito de producción 
Revista de Estudios en Sociedad, Artes y Gestión Cultural www.terciocreciente.com

http://revistaselectronicas.ujaen.es/index.php/RTC
Enero 2017

Investigación problema de la crisis migratoria en Europa; sobre todo, a partir del 2015, año en el que el nivel de violencia hacia los civiles, y la crisis humanitaria por falta de suministros básicos, indujo al pueblo sirio al éxodo masivo de su país.

Según datos ofrecidos por la Organización Internacional de Migraciones (IOM), se estima que tan sólo desde enero del 2016 hasta el fecha del 10 de julio, la migración por mar ha supuesto un total de 238,220 llegadas a territorio europeo y, que desde el conflicto, ha habido un incremento del drama migratorio pues, "en lo que va de este año un estimado de 2.942 muertes se han registrado, en comparación con 1.838 en los primeros seis meses de 2015 y 1906 hasta el 12 de julio del año pasado.” (IOM, 2016)

Bajo este contexto hallamos múltiples problemáticas. Como punto más importante, obviamente, la cantidad de personas que esperanzadas, confían en su suerte, pero por desgracia mueren en el intento ahogadas en altamar. Por otro lado, miles de refugiados desamparados que vagan por Europa en busca de un nuevo hogar y la infinitud de problemas políticos y sociales que ello acarrea ${ }^{14}$.

Nadie negará que una de las imágenes seculares más angustiantes de esta crisis humanitaria, es la fotografía que capta, en septiembre de 2015, el cuerpo inerte de Aylan Kurdi; un niño sirio de 3 años de edad que yacía postrado en la orilla de la playa boca abajo. Para muchos, un ahogado más en las costas turcas de Bodrum, en el mar Egeo. Para otros, un símbolo del drama migratorio ya que reflejaba la más cruda realidad a la par que, sensibilizaba a la sociedad Europea sobre la seriedad del tema y la necesidad de comenzar una verdadera política migratoria común fundamentada en la solidaridad entre los pueblos.

La pieza que presento, "Various Small Shipwreck... and big Fires" (2016), constituye una pieza más del movimiento ruschiano del que hemos estado hablando. Una forma de producción fundamentada en el apropiacionismo, bajo la mira de instaurar por medio del fotolibro y el poder relator de la imagen, un claro gesto denunciativo frente a esta serie de problemáticas migratorias.

En esta ocasión, el juego retórico instaurado es el de la antítesis. Al contrario de otras piezas, el manejo del fuego es relegado hasta el final invirtiéndose los papeles al manejarse el elemento del agua como protagonista. En este caso, el libro lo conforman un total de 15 imágenes dispuestas exactamente igual que lo hizo Ruscha, salvo por un detalle cromático. En lugar de fotografías en blanco y negro sobre fondo amarillo, las relativas al mar, catorce en total, son azuladas. La última, por el contrario, tiene un acabado amarillo. Por otra parte, todas las fotografías de autoría ajena15 nos revelan de forma cruda la triste realidad. Cabe añadir, fotografías que decidimos tomar, por su fuerza y cercanía hacia los hechos. Imágenes que nos invitan a imaginar lo atroz de lo inenarrable; prácticamente representaciones de eventos límite que nos hablan desde el otro lado de la barbarie y el horror acontecido, recordándonos nuestra posición privilegiada. Un libro que indirectamente nos advierte acerca de la comodidad aburguesada de la que gozamos como lectores. Un espacio de confort que aprovechándose de nuestra inevitable pulsión escópica, nos recuerda en dónde estamos y en cierto modo, quiénes somos.

Asimismo, es importante destacar que en términos secuenciales, manejamos el mismo estilo ruschiano. Imágenes monotemáticas dispuestas linealmente sobre el mismo 
Enero 2017

Investigación escenario, la playa que monocromáticamente nos muestra varios cuerpos inertes; hombres, mujeres y niños con los que buscamos llevar al alma del lecto-espectador al devastamiento, a un profundo estado de afección16.

Un juego retórico antítetico respecto a la obra de Ruscha ya que, en lugar de romper la secuencia lineal de los fuegos con un vaso de leche, la quiebra se obtiene con el juego de dos fotografías. La penúltima, la fotografía que muestra el cuerpo inerte de Aylan Kurdi de la que ya hablamos, y la última, la imagen de una gigantesca explosión nuclear. Obviamente, en alusión directa a cómo los intereses propios de países beligerantes causan crisis humanitarias como las migratorias

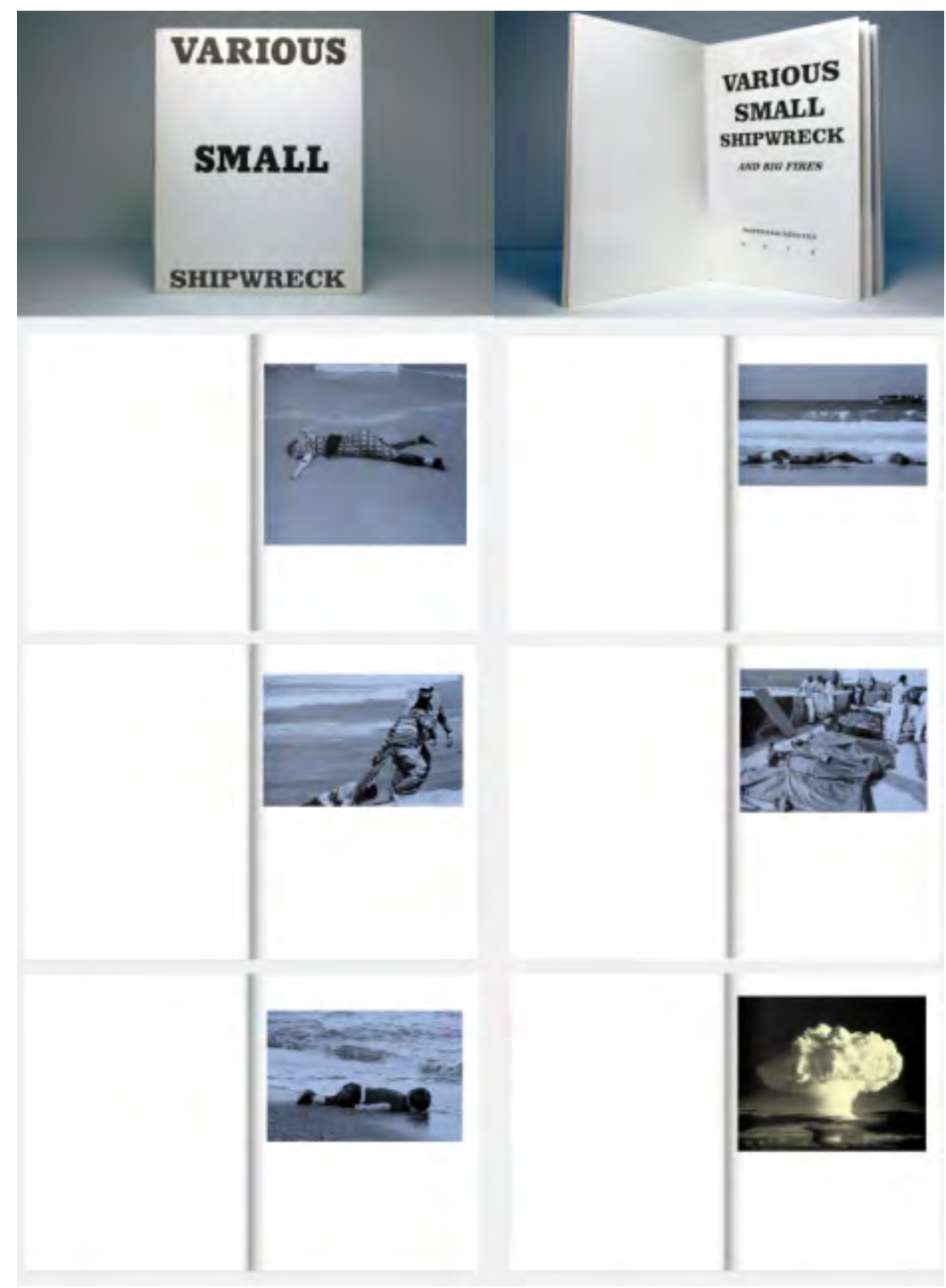

Fig. 4. "Various Small Shipwreck... and big Fires" (2016), Autor. Libro de artista. Formato 17,8 × $14 \mathrm{~cm}$. 44 pp. Ciudad Juárez, México. Flipbook; edición abierta. Impresión a demanda. Imágenes del libro: Autoría propia. 
Revista de Estudios en Sociedad, Artes y Gestión Cultural www.terciocreciente.com

http://revistaselectronicas.ujaen.es/index.php/RTC
Enero 2017

Investigación

\section{3.- Reflexión final}

El libro como medio de comunicación y divulgación de conocimiento, no sólo constituye una forma de legitimación y reconocimiento sociocultural sino también, una forma de transmitir aquello que consideramos digno de ser memorable. El libro, a manos del Arte, es un medio relator que nos exhorta a una lectura crítica, sensible y conceptual acerca de quiénes somos y cuáles son realmente nuestros valores como seres humanos; un espacio, si cabe, posibilitador de procesos de alteridad y actos de revisión intimista entre el artista y el lector, sus recuerdos y su visión del pasado, presente y futuro.

Al ocaso del presente texto, se hace patente que el interés de muchos artistas de apropiarse, resignificar y recontextualizar la obra de Ed Ruscha, ha sido en pro de homenajear su elegante forma de romper con diversos paradigmas impuestos. Por ejemplo, identificamos cómo cada una de las resignificaciones de "Various Small Fires", sobre todo, de la mano de artistas como Thomas Galler (2009), Scott McCarney (2010), Marcella Hackbard (2010) y Autor (2016), nos hablan de la necesidad de generar una memoria colectiva que nos cohesione conscientemente frente a las problemáticas de urdimbre global, sensible y anacrónica en torno a valores como el respecto, la bondad, la solidaridad o la libertad.

Bajo esta tesitura, cada una de sus piezas convergen al punto de considerar al libro como un espacio para la mnemotecnia, y a la memoria como ese fenómeno sensorial que se refigura constantemente conforme al contexto en el que se recuerda algo, pues "los recuerdos son imágenes mentales que combinan nuestra propia experiencia vivida con relatos y versiones de otros -pues toda memoria es colectiva, no meramente individual-, y (...) van cambiando en cada presente que los evocamos." (Vargas, 2016, s.p.)

Del mismo modo, los actos apropiacionistas de obras como "Various Small Fires", vienen a conformar una clara manifestación cultural sobre nuestras propias estrategias discursivas actuales tales como el remake. Una forma de producción inherente a la apropiación como estrategia alegórica que muchos de nosotros hemos venido utilizado.

Estamos seguros, que ninguno de los autores analizados pretendió suplantar la identidad ni el mensaje ruschiano. De hecho, a partir de dicho análisis, creemos que todos buscaron generar sus propias narrativas aprovechando la distancia temporal que separaba su presenticidad y la de Ruscha. Es decir, entre los modelos de producción editorial y los valores conceptuales y estéticos de la época en la que Ed Ruscha iniciaba el posicionamiento de un nuevo género artístico que por medio del libro posibilitaba un arte más cercano, intimista y democrático, y el de cada autor nombrado. Artistas que, inevitablemente secundamos las prácticas de creación y producción editorial de un mundo cada vez más globalizado y dominado por los medios de comunicación; un mundo constantemente modulado al son expansionista de las tecnologías digitales, la producción editorial estandarizada de tiraje cada vez más corto y a demanda. Si cabe, una actualidad acomodada en el confort para algunos de nosotros e imperada por la injusticia para muchos otros; un escenario que forzosamente nos invita a tomar partido, al menos, a través del Arte y el Libro. Al cabo, ¿qué es sino el arte? ... una forma más de resistencia. 


\section{Notas}

El término Replicante, lo tomamos de la película de Blade Runner. Quien haya visto esta película, sabrá que el mensaje que Ridley Scott nos quería hacer ver es que las máquinas, ঢlos replicantes $\square$, se habían vuelto más humanas, sensibles y emotivas que el propio hombre. Una humanidad que con el tiempo parecía haber abandonado el interés por conocer la respuesta a la razón de su existencia; así como olvidado el verdadero sentido de la vida y de la libertad.

2 Una de las exposiciones más importantes que muestran el impacto que Ruscha ha suscitado en las siguientes generaciones, se celebró en el Cabinet Du Livre D’Artiste de la Université Rennes de Francia, con el título de "Follow-ed (after hokusai)", entre el 28 de septiembre y el 3 de diciembre de 2015. Una muestra expositiva que aglutinó cerca de 400 piezas de la colección de Michalis Pichler y Tom Sowden.

3 "Muchas de las fotografías en los libros, por cierto, no fueron hechas por el mismo Ruscha, sino por colaboradores tales como Joe Goode, Patrick Blackwell, Art Alanis (las fotos aéreas de los estacionamientos) y Jerry McMillan.” Decía Ruscha: «No es realmente importante quién tome las fotografías», "Ni siquiera las miro como fotografías; son solamente imágenes para llenar un libro».” (citado en Coleman, 2016, p. 3)

4 “Twetysix Gasoline Station” (1962) por ejemplo, llegó a venderse por 3 dólares y medio, aunque su precio promedio en un inicio fue de cincuenta dólares. (Engberg y Phillpot, 1999)

5 En mismo tenor enunciativo, sus portadas destacan por la simpleza y literalidad de los títulos. Grandes titulares que, además, dan muestra del amor de Ruscha por el rotulismo y su anterior desempeño como diseñador gráfico.

6 Por ejemplo, en su famosa obra “Twentysix Gasoline Stations” (1962), considerada por algunos como el primer libro de artista, la calidad técnica de las fotografías no está a la altura de la edición del libro, la cual Ruscha maneja siempre con gran destreza e impecabilidad. En este sentido, se identifican problemas de encuadre y del manejo de la luz trabajados así intencionalmente.

7 Según el semiólogo Omar Calabrese (1987), gustos imperados por la estética de la repetición, las técnicas discursivas de la enunciación, la diferenciación y la sublimidad causada por la incertidumbre de no saber qué es aquello que se está viendo. Además del manejo de formas de producción como la autorreferencialidad o las relaciones transdiscursivas inherentes a los juegos intertextuales, paratextuales, metatextuales, etc. En suma, relativos a las prácticas del apropiacionismo, el remix o la cita.

8 El término de ícono secular se ha acotado temáticamente a aquellas imágenes fotográficas "reconocidas y compartidas por un grupo extenso" (Merlo, 1996, p. 12) a tal grado que ilustran, representan e incluso traducen, nuestra identidad colectiva como país, como comunidad, como vecindario, etc., puesto que constituyen un imaginario compartido ya que "representan la visibilidad de un evento" (Merlo, 2016, p. 11), una idea o ideología. Por ejemplo, hablamos tildar de íconos seculares, la fotografía del Che Guevara como ícono de los movimientos contraculturales o la fotografía de Henri Cartier-Bresson de una mujer con una margarita frente a hombres armados como símbolo de paz. Por nuestra cuenta, consideramos extensible 


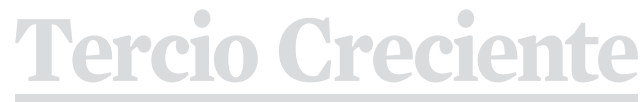

ISSN: $2340-9096$

DOI: $10.17561 /$ rtc.mextra1.2
Revista de Estudios en Sociedad, Artes y Gestión Cultural

www.terciocreciente.com

http://revistaselectronicas.ujaen.es/index.php/RTC
Enero 2017

Investigación

el concepto a piezas artísticas. En el mismo tenor, se abre la posibilidad de reconocer algunos trabajos de Ruscha como íconos seculares ya que representan las nuevas formas de generar discursos artísticos a través de un medio como el libro. Obras que han obtenido el grado de iconicidad por su amplio reconocimiento y difusión dentro del género de los libros de artista, y otros medios de comunicación, a la par que, piezas apropiadas a posteriori una y otra vez por diferentes tipos de usuarios o creativos.

9 Al respecto decía el propio Ruscha: «El fuego también ha sido parte de mi trabajo anterior, he hecho pinturas sobre el fuego y han sucedido pequeñas cosas relacionadas con el fuego en mi vida, no como experiencia, ni de una forma negativa, no he tenido ninguna catástrofe vinculada al fuego, pero la imagen del fuego ha sido siempre muy fuerte en mi trabajo y, por tanto, esto culmina en este pequeño libro aquí [Various Small Fires, que contiene 16 imágenes — tuberías en llamas, cigarrillos, un destello, un encendedor en llamas]. Es probablemente uno de los libros más extraños, parece como si destacara, incluso mucha gente me ha hablado acerca de cómo se aparta de los demás porque es más introvertido, asumo; introvertido, menos llamativo, probablemente más sin sentido que cualquiera de mis otros libros, si comprendes lo que quiero decir». (Ruscha en Coleman, 2016, p. 7)

10 En ese sentido, nos preguntamos: ¿Qué es lo que estallará en conflicto? Las intenciones del autor se tornan insondables tras el manejo de esta forma de secuenciar las imágenes considerando el contexto en el que se ubica su edición a finales de los sesenta. ¿De qué nos está hablando Bruce Nauman? ¿Nos habla de conflictos bélicos? ¿De conflictos de autoría y de la apropiación indebida de la obra de Ruscha? ¿De estrategias para la revalorización de las obra de ambos en el mercado del arte?

11 Todas las imágenes pueden verse en línea desde: http://newcatalogue.net/projects/variousfires/

12 El texto original dice así: "At once horrifying and strikingly beautiful, the book questions the rol of sensationalistic imagery within media representations that arte complicit with the culture of spectacle." (Traducción por la autora)

13 Los disturbios alcanzaron tal magnitud que, apenas unos días, se declaró la muerte de 55 personas, más la destrucción de 10,000 negocios a causa del fuego.

14 Algunos países han mostrado un sentido más fraternal que otros. Tal es el caso de Alemania. Un país abanderado de fraternidad que ha abierto sus puertas a miles de refugiados, generando con ello, como contraparte, problemas de sustentabilidad y falta de abastecimiento de recursos, e incluso, el renacimiento de insurrectos ultraderechas y xenófobos.

15 En línea con la práctica apropiacionista, las imágenes están sustraídas directamente de la web. La autoría de las fotografías corresponden a: Migrant Report (mujer tendida boca abajo), Marina Italiana (naufragio), Fotografías de AP Images (Associated Press Images) (inmigrantes ahogados en Sicilia, Italia); de la AFP (Asociación de Fotógrafos Profesionales) de España, ocho imágenes (cuerpos hallados en las costas de Qarabouli cerca de Trípoli); de ANSA DTM, EPA (Agenzia Nazionale Stampa Associata y European Pressphoto Agency) del fotógrafo Nino Randazzo (filas de cadáveres en el puerto de Lampedusa); y por último, la famosa fotografía de Aylan Kurdi 
por Nilüfer Demir. Finalmente, la obra se cierra con una imagen de AP/Archivo (Archive Associated Press) (Explosión del ensayo nuclear)

16 Estas imágenes nos recuerdan al discurso de Didi-Huberman (2004) quien en torno a las fotografías obtenidas del campo de concentración de Auschwitz, nos hablaba en su obra Imágenes, pese a todo de imágenes inexactas, de fragmentos de la realidad. Decía Huberman: "lo que vemos (...) es todavía demasiado poco en comparación con lo que sabemos (muertos a millares...)" p. 59. "Imaginarlo pese a todo, algo que nos exige una difícil ética de la imagen: ni lo invisible por excelencia (pereza del esteta), ni el icono del horror (pereza del creyente), ni el simple documento (pereza del sabio). Una simple imagen: inadecuada pero necesaria, inexacta pero verdadera. Verdadera por una verdad paradójica, por supuesto. Yo diría que la imagen es aquí el ojo de la historia por su tenaz vocación de hacer visible.” (p. 67) (...) “Más allá de la muerte como representación accesible” (p. 71)

\section{Referencias}

Calabrese, Omar (1987) La era neobarroca. Madrid: Cátedra

Coleman, A.D., (2016) “Ed Ruscha y la fotografía” En: Revista de Estudios interdisciplinarios de arte y cultura, vol. 3, núm. 1, pp. 71-82

Del Río, Víctor (2002-2003) "Las interpretaciones de Edward Ruscha. Avatares de la fotografíaobjeto.” En: Papel Alpha. Cuadernos de Fotografía y Vídeo, no 6, pp. 3-23. Recuperado desde http://www.victordelrio.net/PDFS/Ensayos/La\%20fotografia\%20objeto.pdf

Didi-Huberman, Georges (2004) Imágenes pese todo. Memoria visual del Holocausto. Barcelona: Ediciones Paidós Ibérica, S.A.

Engberg, Siri y Phillpot, Clive (ed.) (1999) Edward Ruscha: Editions 1959-1999. Catalogue Raisonne. Volume 1: Prints, Books Misc. Volume 2: Essays. Walker Art Center, Vol. 2, p. 60.

Foucault, M. (1990). ¿Qué es autor? México: La letra.

IOM (Organización Internacional para Migraciones) (12/07//2016) "Las llegadas migratorios mediterráneos en 2016: 238,220; Muertes: 2.942” Ginebra. Recuperado desde: http:// missingmigrants.iom.int/mediterranean-migrant-arrivals-2016-238220-deaths-2942

Merlo, Alessandra. (2016) "La memoria en los ojos. Reflexiones sobre imágenes e historia: ¿podemos definir un repertorio colombiano?”. En: Memoria y Sociedad 20, $\mathrm{n}^{\circ} 40$, enerojunio de 2016, pp. 10-24. Recuperado desde: http://dx.doi.org/10.11144/ Javeriana.mys20-40. mori

Zschiegner, Hermann, Brouws, Jeff y Burton, Wendy (eds.) (2013) Various Small Books by Ed Ruscha. Cambridge, MA: MIT Press. 